\title{
Cataract formation following vitreoretinal procedures
}

\author{
This article was published in the following Dove Press journal: \\ Clinical Ophthalmology \\ 23 September 2014 \\ Number of times this article has been viewed
}

Purpose: To evaluate the incidence and prevalence of cataract formation, progression, and extraction in patients that underwent vitreoretinal procedures and to evaluate factors that can potentially predispose patients to postoperative cataracts.

Department of Ophthalmology and Visual Science, Yale University School of Medicine, New Haven, CT, USA

Correspondence: Ron A Adelman Yale Eye Center, 40 Temple Street, 3rd floor, New Haven, CT 06510, USA

$\mathrm{Tel}+\mathrm{I} 2037856444$

Fax +I 2037855909

Email ron.adelman@yale.edu
Materials and methods: The medical records of consecutive patients who underwent vitreoretinal surgery at the Yale Eye Center with at least 6 months of follow-up and no prior intraocular surgery were obtained. Preoperative, intraoperative, and postoperative data were recorded and analyzed in this retrospective observational study. The main outcome measures were defined as cataract extraction, formation, and progression after vitreoretinal procedures. The lens status of the surgical eye was recorded preoperatively and at 1 month, 3 months, 6 months, 12 months, 24 months, and 36 months postoperatively.

Results: A total of 193 eyes of 180 patients fulfilled the inclusion criteria. The percentages of eyes with mild lens change were $96 \%$ after 20 -gauge pars plana vitrectomy (PPV), $72 \%$ after small gauge (23- and 25-gauge) PPV, 38\% after scleral buckle (SB), 38\% after pneumatic retinopexy (PR), and 91\% after PPV plus SB (PPV+SB). Posterior subcapsular and nuclear sclerotic cataracts were the most common with almost all developing within 24 months. There was no statistically significant difference $(P=1.00)$ between the rate of cataract extraction after 20 -gauge (41\%) and small gauge PPV (42\%), but there was a statistically significant difference between PPV and non-PPV (SB, 6\%; PR, 7\%; $P<0.001)$ and PPV and PPV+SB groups (69\%; $P=0.0063)$.

Conclusion: Cataracts were common following PPV regardless of the gauge. SB and PR led to the lowest while PPV+SB led to the highest risk of postoperative cataracts.

Keywords: cataracts, vitreoretinal surgery, vitrectomy, scleral buckle, pneumatic retinopexy

\section{Introduction}

Cataract is commonly reported following 20-gauge pars plana vitrectomy (PPV) with the incidence rate varying from $12.5 \%-80 \%{ }^{1-10}$ While the exact etiology of cataract formation following vitreoretinal procedures is unknown, the high incidence following vitrectomy may relate to increased oxygen tension, altered milieu following vitreous removal, oxidative stress, trauma, and iatrogenic causes. ${ }^{1,2,6,11,12}$

Small gauge (23- or 25-gauge) PPV systems ${ }^{13-15}$ are potentially less risky than 20-gauge PPV systems due to reduced balanced salt solution consumption, lower intravitreal fluid flow, decreased surgical time, and ocular manipulation. ${ }^{8}$ However, the theoretical advantages of small gauge PPV require verification and translation into observable clinical benefit. Other procedures are also effective for the repair of retinal detachment, such as scleral buckle (SB) and pneumatic retinopexy (PR). A comparison of cataract formation following each vitreoretinal procedure would be useful not only to further current knowledge, but also to inform patients in clinical practice. 
Most studies have examined, analyzed, and compared one or two types of vitreoretinal procedures for cataract development. Additional comparisons and information are helpful regarding the rate of postoperative cataracts for: 1) $\mathrm{PPV}, \mathrm{SB}, \mathrm{PR}$, and combined $\mathrm{PPV}$ and $\mathrm{SB}(\mathrm{PPV}+\mathrm{SB})$; and 2) small gauge and 20-gauge PPV. In the following study, we attempt to address these issues by comparing the impact of different surgical strategies on cataract formation, progression, and extraction while evaluating factors that may contribute to cataracts, such as age, comorbidities, and injected intraoperative tamponade medium.

\section{Materials and methods}

The medical records of patients who underwent PPV, SB, $\mathrm{PR}$, or a combination of these procedures between January 1998 and May 2009 at the Yale Eye Center were obtained and reviewed. Patients were eligible for inclusion if they had no prior record of intraocular surgery and were followed for at least 6 months after surgery. Exclusion criteria included previous cataract extraction, traumatic cataract, injured lens during surgery, and previous intraocular procedure. The study was performed with adherence to Health Insurance Portability and Accountability Act guidelines. The Yale University Institutional Review Board waived the need for formal approval of this retrospective study. Preoperative, intraoperative, and postoperative data were recorded from a detailed chart review. Preoperative data included age, sex, ethnicity, comorbid medical conditions, affected eye, ophthalmic diagnosis, visual acuity, type and severity of preexisting lens changes, and status of the fellow eye. Intraoperative data included the type of vitreoretinal procedure, intraoperative complications and any use of gas, or silicone oil as a tamponade agent. Postoperative data consisted of intraocular pressure, length of follow-up, visual acuity, type and severity of lens changes, and the need for additional ocular surgery including cataract extraction. For patients who underwent vitreoretinal procedure on both eyes, each eye was analyzed separately.

Cataract was categorized by type and severity. Type included posterior subcapsular (PSC), nuclear sclerotic (NSC), and anterior cortical cataracts (ACC). Cataract severity, based on grading from the vitreoretinal physician at the time of patient examination, was recorded as clear $(0)$, mild (1+), moderate (2+), severe (3+), and very severe (4+). Progression of cataract was recorded by change in severity. For each eye undergoing vitreoretinal surgery, lens clarity was recorded before surgery and at 1 month, 3 months, 6 months, 12 months, 24 months, and 36 months after surgery.
Cataract formation and progression were classified as mild or moderate, with mild defined as a change in lens opacity by a value of 1 and moderate defined as a change in lens opacity by a value of 2 or more. The formation of new cataract, progression of existing cataract, and the need for cataract extraction for each type of vitreoretinal procedure were quantified and analyzed. Cataract surgery was performed to improve the visual function of eyes with clinically significant cataract progression and functional visual impairment.

Appropriate methods were selected for statistical analyses using GraphPad Prism statistical software. Two-tailed Fisher's exact test was used in the contingency table analysis to evaluate the differences in the rate of postoperative cataract extraction among different groups. The Kruskal-Wallis test was used to investigate differences in the means between several groups. In all tests, we considered a significance level of $P>0.05$.

Sensitivity analysis was performed to investigate the potential effect of including individuals with both eyes and those $<40$ years old since the incidence and progression of cataracts increase with age. All analyses were rerun after first randomly eliminating one eye of the 13 patients who contributed two eyes, and then again after eliminating an additional 43 patients who were $<40$ years old. The age of 40 years was set as the cutoff point due to the relatively low risk of cataracts below this age and the need to maintain a reasonable sample size for analysis.

\section{Results}

A comprehensive chart review identified 107 males and 73 females who fulfilled the required eligibility criteria, with a total of 193 eyes (100 left eyes and 93 right eyes). The mean age of the study patients was 41.42 years old with a range of 3-84 years old. The racial distribution of the subjects was 95 (52.8\%) Caucasian, 42 (23.3\%) African American, $38(21.1 \%)$ Hispanic, and five (2.8\%) Asian. Sixty-six (36.7\%) patients had diabetes and $83(46.1 \%)$ had hypertension. Fifty-nine eyes of 53 patients underwent 20 -gauge PPV, 50 eyes of 47 patients underwent small gauge PPV, 35 eyes of 32 patients underwent SB, 14 eyes of 13 patients underwent PR, and 35 eyes of 35 patients underwent PPV+SB. The length of patient follow-up ranged from 6-78 months with an average of 23.75 months. The average length of follow-up in months was 31.64 for 20-gauge PPV, 16.44 for small gauge PPV, 27.21 for PR, 21.17 for SB, and 22.06 for $\mathrm{PPV}+\mathrm{SB}$. The characteristics of the subjects and their eyes are summarized in Table 1. The preoperative lens grading is displayed in Table S1. Of all eyes, only one had a lens grading 
Table I Demographic information of patients and ophthalmic data of surgical eyes

\begin{tabular}{|c|c|c|c|c|c|c|c|}
\hline & 20-gauge PPV & Small gauge PPV & SB & PR & $\mathbf{P P V}+\mathbf{S B}$ & Total & $P$-value \\
\hline \multicolumn{8}{|l|}{ Sex, n (\%) } \\
\hline Male & $34(64.2)$ & $26(55.3)$ & $21(65.6)$ & $8(6 \mid .5)$ & I8 (5I.4) & $107(59.4)$ & 0.684 \\
\hline Female & $19(35.8)$ & 21 (44.7) & II (34.4) & $5(38.5)$ & $17(48.6)$ & $73(40.4)$ & \\
\hline \multicolumn{8}{|l|}{ Age (years) } \\
\hline Mean \pm SD & $50.47 \pm 14.13$ & $50.57 \pm 15.85$ & $38.44 \pm 18.56$ & $56.62 \pm 14.03$ & $43.34 \pm 17.29$ & $41.42 \pm 16.77$ & 0.00167 \\
\hline \multicolumn{8}{|l|}{ Eye, n (\%) } \\
\hline Left & $30(50.8)$ & $27(54.0)$ & $21(60.0)$ & $7(50.0)$ & $15(42.9)$ & $100(5 \mathrm{I} .8)$ & 0.699 \\
\hline Right & $29(49.2)$ & $23(46.0)$ & $14(40.0)$ & $7(50.0)$ & $20(57.1)$ & $93(48.2)$ & \\
\hline \multicolumn{8}{|l|}{ Ethnicity, n (\%) } \\
\hline White & $23(43.4)$ & $15(31.9)$ & $22(68.8)$ & II (84.6) & $24(68.6)$ & $95(52.8)$ & 0.00127 \\
\hline Black & $17(32.1)$ & $13(27.7)$ & $6(18.8)$ & I (7.7) & $5(14.3)$ & $42(23.3)$ & \\
\hline Hispanic & II (20.7) & $19(40.4)$ & $2(6.2)$ & I (7.7) & $5(14.3)$ & $38(21.1)$ & \\
\hline Asian & $2(3.8)$ & $0(0)$ & $2(6.2)$ & $0(0)$ & I (2.8) & $5(2.8)$ & \\
\hline \multicolumn{8}{|c|}{ Comorbidity, n (\%) } \\
\hline DM & $28(52.8)$ & $29(61.7)$ & $5(15.6)$ & $0(0)$ & $4(11.4)$ & $66(36.7)$ & $<0.001$ \\
\hline HTN & 31 (58.5) & $33(70.2)$ & 7 (2I.9) & $3(23.1)$ & $9(25.7)$ & $83(46.1)$ & $<0.001$ \\
\hline
\end{tabular}

Abbreviations: PPV, pars plana vitrectomy; SB, scleral buckle; PR, pneumatic retinopexy; PPV+SB, combined pars plana vitrectomy plus scleral buckle; n, number; $\mathrm{SD}$, standard deviation; DM, diabetes mellitus; HTN, hypertension.

greater than 2 before vitreoretinal surgery. The preoperative ophthalmic diagnosis is displayed in Table 2.

Eyes were evaluated based on their change in lens status. The cumulative fractions of mild and moderate cataract changes after vitreoretinal surgery are shown in Table 3. The cumulative percentage of eyes with mild or moderate changes at 36 months was $96 \%$ for 20 -gauge PPV, $72 \%$ for small gauge PPV, $38 \%$ for SB, $38 \%$ for PR, and $91 \%$ for $\mathrm{PPV}+\mathrm{SB}$. The cumulative percentage of eyes with moderate lens changes at 36 months was $58 \%$ of eyes after 20 -gauge PPV , 30\% after small gauge PPV, $6 \%$ after SB, $0 \%$ after PR, and $66 \%$ after PPV+SB. The majority of eyes with mild and moderate lenticular changes developed opacification within 24 months postoperatively.

On average, eyes from all the vitreoretinal procedure groups demonstrated lens opacification after surgery. The

Table 2 Preoperative diagnoses of surgical eyes

\begin{tabular}{ll}
\hline Diagnosis & Eyes number (\%) \\
\hline Rhegmatogenous retinal detachment & $83(43.0)$ \\
Diabetic tractional retinal detachment & $28(14.5)$ \\
Diabetic vitreous hemorrhage & $23(11.9)$ \\
Nondiabetic vitreous hemorrhage & $12(6.2)$ \\
Retinitis & $1 \mathrm{I}(5.7)$ \\
Macular hole & $10(5.2)$ \\
Epiretinal membrane & $10(5.2)$ \\
Uveitis & $6(3.1)$ \\
Sickle cell retinopathy with vitreous hemorrhage & $4(2.1)$ \\
Stickler syndrome with retinal detachment & $4(2.1)$ \\
Central retinal vein occlusion & $2(1.0)$ \\
Total & $193(100.0)$ \\
\hline
\end{tabular}

mean and standard deviation of changes in lens grading from preoperative evaluation to the final examination after the vitreoretinal surgery was $0.51 \pm 0.67$ for $\mathrm{SB}, 0.50 \pm 0.52$ for PR, 1.71 \pm 1.01 for 20-gauge PPV, $1.18 \pm 1.06$ for small gauge $\mathrm{PPV}$, and $2.06 \pm 1.12$ for PPV+SB. The median changes in lens grading were 0.25 for $\mathrm{SB}, 0.50$ for $\mathrm{PR}, 2.0$ for 20-gauge PPV, 1.0 for small gauge PPV, and 2.0 for PPV+SB.

Overall, NSC and PSC were the most frequent types of primary cataracts developed postoperatively (number $[\mathrm{n}]=69$ each) with ACC being the least common ( $\mathrm{n}=6)$. There was no change in the lens status of 49 (25.39\%) eyes postoperatively. While NSC development and progression were seen after all types of vitreoretinal procedures $(32 \%-57 \%$ of eyes), PSC was seen primarily in vitrectomized eyes (36\%-54\%) but minimally, if at all, in eyes after SB or PR $(0 \%-5.7 \%)$. The distribution of cataract types is displayed in Table 4 . The types of cataracts developed in patients 50 years old or older were $45.1 \%$ PSC, $52.4 \%$ NSC, $2.5 \%$ ACC as compared to $52.5 \%$ PSC, $41.0 \%$ NSC, and $6.6 \%$ ACC in patients $<50$ years old.

The overall rate of cataract extraction after vitreoretinal surgery was $37.3 \%$. Cataract extraction was performed in two $(5.71 \%)$ out of 35 eyes after SB, one (7.14\%) out of 14 eyes after PR, 24 (40.68\%) out of 59 eyes after 20-gauge PPV, 21 (42.00\%) out of 50 eyes after small gauge PPV, and $24(68.57 \%)$ out of 35 eyes after PPV+SB. The cumulative fraction of cataract extraction as a function of time is displayed in Figure 1. The average length of time between vitreoretinal surgery and cataract removal was 17.90 months for 20-gauge PPV, 8.14 months for small gauge PPV, 
Table 3 Cumulative fraction of mild and moderate lens changes of surgical eyes after vitreoretinal procedures

\begin{tabular}{|c|c|c|c|c|c|c|}
\hline & I month & 3 months & 6 months & 12 months & 24 months & 36 months \\
\hline \multicolumn{7}{|l|}{ Mild change } \\
\hline 20-gauge PPV & 0.321 & 0.604 & 0.774 & 0.943 & 0.962 & 0.962 \\
\hline Small gauge PPV & 0.277 & 0.617 & 0.660 & 0.702 & 0.723 & 0.723 \\
\hline SB & 0.219 & 0.250 & 0.344 & 0.344 & 0.375 & 0.375 \\
\hline PR & 0.154 & 0.154 & 0.231 & 0.385 & 0.385 & 0.385 \\
\hline $\mathrm{PPV}+\mathrm{SB}$ & 0.429 & 0.629 & 0.714 & 0.857 & 0.914 & 0.914 \\
\hline \multicolumn{7}{|c|}{ Moderate change } \\
\hline 20-gauge PPV & 0.113 & 0.302 & 0.396 & 0.453 & 0.547 & 0.585 \\
\hline Small gauge PPV & 0.085 & 0.170 & 0.298 & 0.298 & 0.298 & 0.298 \\
\hline SB & 0.000 & 0.000 & 0.000 & 0.031 & 0.063 & 0.063 \\
\hline PR & 0.000 & 0.000 & 0.000 & 0.000 & 0.000 & 0.000 \\
\hline $\mathrm{PPV}+\mathrm{SB}$ & 0.086 & 0.314 & 0.429 & 0.571 & 0.657 & 0.657 \\
\hline
\end{tabular}

Abbreviations: PPV, pars plana vitrectomy; SB, scleral buckle; PR, pneumatic retinopexy; PPV+SB, combined pars plana vitrectomy plus scleral buckle.

11.00 months for SB, 27.50 months for PR, and 9.71 months for PPV+SB. This difference may be partially due to the variable follow-up time between the groups.

There was no statistically significant difference in the rate of cataract extraction between patients who underwent the 20-gauge and the small gauge PPV system $(P=1.00)$. However, the rate of cataract extraction was significantly different between PPV and PPV+SB $(P=0.0063)$, PPV-only and PR $(P=0.0165)$, and PPV-only and SB $(P<0.0001)$.

The rate of cataract extraction was not significantly impacted by sex, or by diagnosis of hypertension and/ or diabetes. Forty-nine (48.04\%) of 102 eyes in patients 50 years or older compared to $28(30.77 \%)$ of 91 eyes in patients $<50$ years old underwent cataract surgery $(P=0.0184)$. Cataract extraction was performed in $21(44.7 \%)$ of 47 eyes with gas tamponade, $14(58.3 \%)$ of 24 eyes with silicone oil tamponade, and 15 (41.7\%) of 36 eyes without tamponade. Cataract extraction rates were not significantly different between procedures that utilized silicone oil and gas tamponade ( $P=0.3222)$, silicone oil and no tamponade ( $P=0.2922)$, or gas and no tamponade $(P=0.8260)$. The mean and standard deviation of the change in lens status for gas, silicone oil, and no tamponade were $1.44 \pm 1.10,1.98 \pm 1.01$, and $1.17 \pm 0.94$, respectively. The median values of the lens changes were 1.0 for gas, 2.0 for silicone oil, and 1.0 for no tamponade. There were statistically significant differences in the change in lens status between silicone oil and gas tamponade $(P=0.023)$ and silicone oil and no tamponade $(P=0.0024)$, but not between gas and no tamponade $(P=0.261)$.

The visual acuity of patients before and after both vitreoretinal procedure and cataract surgery was analyzed using the logarithm of the minimum angle of resolution (LogMAR) scale. On average, the visual acuity of patients increased after vitreoretinal surgery, but it subsequently worsened over time. Worsening vision led to the need for cataract surgery, after which vision was again restored (Figure 2), except for patients who received SB only. The mean and standard deviation of postoperative intraocular pressure ( $\mathrm{mmHg}$ ) at first follow-up visit 1 day following surgery was $17.46 \pm 6.45$ for 20 -gauge PPV, $15.68 \pm 8.53$ for small gauge PPV, $15.36 \pm 9.47$ for PR, $18.26 \pm 6.28$ for SB, and $20.81 \pm 10.83$ for $\mathrm{PPV}+\mathrm{SB}$, with significant difference observed between the procedures $(P=0.040)$.

Sensitivity analyses were carried out to investigate how individuals who contributed two eyes and were $<40$ years old influenced the results. The results from these analyses were essentially the same as the original. The only difference was there was no longer a statistically significant difference in the

Table 4 Types of cataracts developed or progressed in surgical eyes after vitreoretinal surgery

\begin{tabular}{llllll}
\hline & Nuclear sclerotic & Posterior capsular & Anterior cortical & None & Total \\
\hline 20-gauge PPV & $20(33.90)$ & $30(50.85)$ & $3(5.08)$ & $6(10.17)$ & 59 \\
Small gauge PPV & $16(32.00)$ & $18(36.00)$ & $2(4.00)$ & $14(28.00)$ & 50 \\
SB & $13(37.14)$ & $2(5.71)$ & $0(0)$ & $20(57.14)$ & 35 \\
PR & $8(57.14)$ & $0(0)$ & $0(0)$ & $6(42.86)$ & 14 \\
PPV+SB & $12(34.29)$ & $19(54.29)$ & $1(2.86)$ & $3(8.57)$ & 35 \\
Total & 69 & 69 & 6 & 49 & 193 \\
\hline
\end{tabular}

Note: Values are presented as $n(\%)$.

Abbreviations: PPV, pars plana vitrectomy; SB, scleral buckle; PR, pneumatic retinopexy; PPV+SB, combined pars plana vitrectomy plus scleral buckle; $n$, number. 


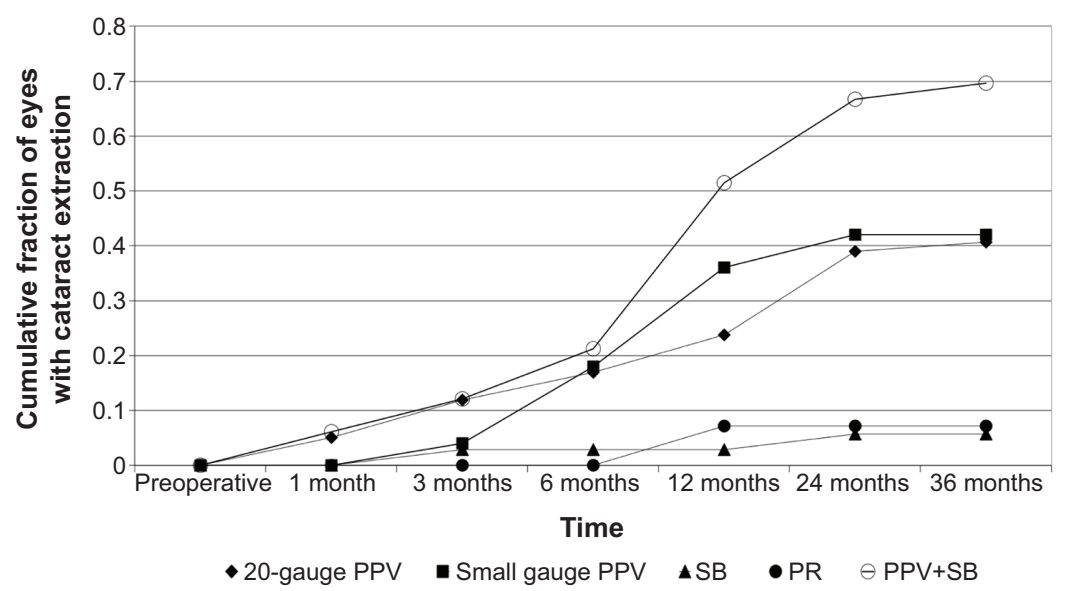

Figure I Cataract extraction after vitreoretinal procedures.

Notes: The cumulative fraction of eyes that underwent cataract surgery at various time points after vitreoretinal procedure showed that cataract surgery was commonly performed within 2 years postoperatively. PPV+SB had the highest rate of cataract extraction at $69 \%$, while SB and PR had the lowest rates at $6 \%$ and $7 \%$, respectively. A significant and similar proportion of eyes that underwent 20 -gauge $(41 \%)$ and small gauge $(42 \%)$ vitrectomy needed cataract surgery postoperatively.

Abbreviations: PPV, pars plana vitrectomy; SB, scleral buckle; PR, pneumatic retinopexy; PPV+SB, combined pars plana vitrectomy plus scleral buckle.

change in lens status between silicone oil and gas tamponade $(P=0.168)$ after eliminating patients who were $<40$ years old and who contributed two eyes.

\section{Discussion}

In this study, eyes that underwent PPV+SB had the most lenticular changes, followed by 20 -gauge PPV and small gauge PPV. In contrast, SB and PR caused very little postoperative lens opacification. This was reflected in the absolute amount of lens grading change and the fraction of eyes developing mild and moderate lenticular opacification.

Despite theoretical advantages, ${ }^{16,17}$ small gauge PPV resulted in a high rate of cataract progression and formation postoperatively, which was not statistically different when compared with 20-gauge PPV in our analysis. Supporting evidence for cataract reduction using small gauge PPV is

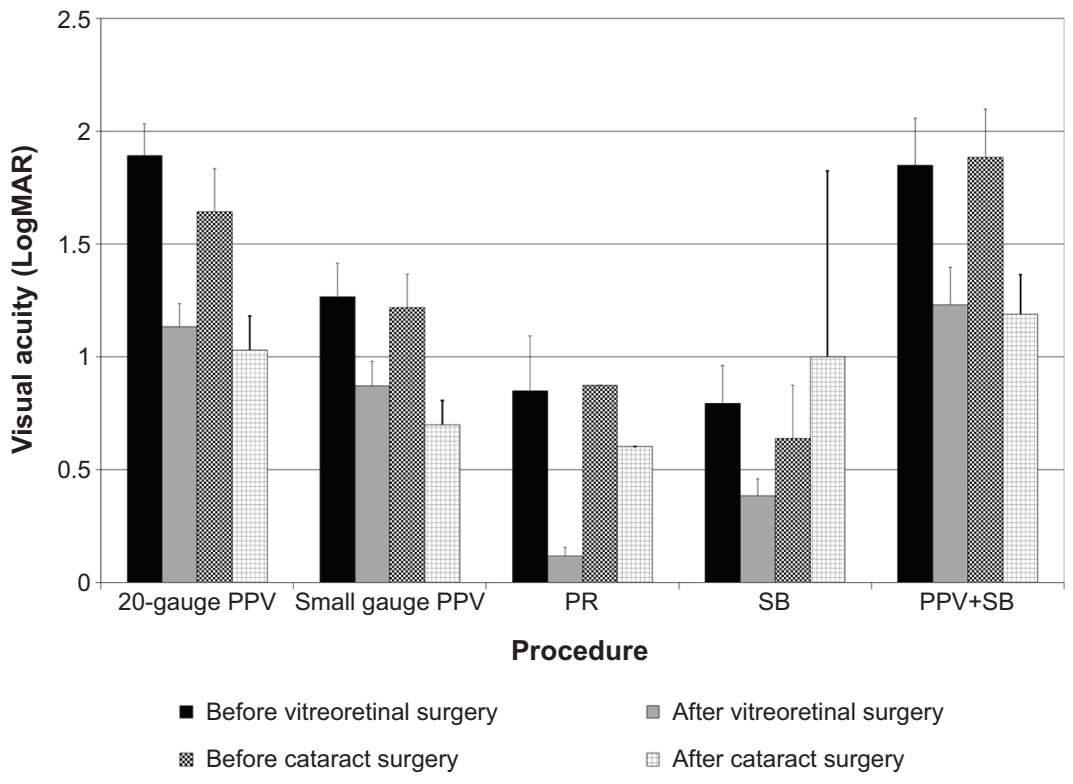

Figure 2 Visual acuity of the surgical eye.

Notes: For the surgical eyes that underwent each vitreoretinal procedure, the average visual acuity improved after vitreoretinal surgery with subsequent deterioration postoperatively due to cataract formation or progression, as evidenced by improvement following cataract surgery. The exception is the SB group, where the mean visual acuity decreased after cataract surgery, which is due to the small sample size $(n=2)$ with one eye showing improvement while the other showed deterioration. Mean and standard error of the visual acuity using the LogMAR scale is shown.

Abbreviations: LogMAR, log of the minimum angle of resolution; PPV, pars plana vitrectomy; PR, pneumatic retinopexy; SB, scleral buckle; PPV+SB, combined pars plana vitrectomy plus scleral buckle; $n$, number. 
unclear. ${ }^{8,18-20}$ In studies that exclusively examined the effects of small gauge PPV, the postoperative cataract rate ranged from $22.7 \%-79.3 \% .^{21-31}$ This is a comparable range to that of the 20-gauge PPV of $12.5 \%-80 \%,{ }^{1-10}$ indicating that cataract is a significant complication of both small gauge and 20-gauge PPV. Our findings are consistent with those from previous work, which showed that $\mathrm{PR}^{32-40}$ and $\mathrm{SB}^{41-45}$ are less risky than PPV in inducing postoperative cataracts, and they could be considered as the surgical modality when appropriate. Because PPV+SB is used in more difficult cases, this may explain the particularly high risk of cataracts after surgery in this study and another study. ${ }^{46}$

We found that eyes that underwent PPV had the largest change in lens opacification during the first 6 months after surgery, with most changes occurring by 24 months. This is consistent with other investigators' findings that most patients develop moderate or visually significant lenticular opacification within 2 years after vitreoretinal surgery, including a significant percentage of patients who develop cataracts within the first 6 months. ${ }^{47-49}$ The data indicate that cataracts develop relatively quickly in the postoperative period.

We found no significant difference in the rate of cataract extraction between 20-gauge and small gauge PPV. According to prior research, the rate of postoperative cataract extraction for 20-gauge PPV varies significantly, ranging from $23 \%-92 \% .^{10,19,26,47-52}$ There is also high variation in the rate of cataract extraction for small gauge PPV with reported values of $23 \%-80 \%$. $^{19,22,24,26,28,30,31,53,54}$ These results indicate that visually impairing cataract development after PPV likely depends on other factors such as oxygen level in the vitreous cavity, the amount of vitreous removed, the amount of inflammation due to the ocular disease and operation, and the length and difficulty of surgery, rather than the exact gauge of the PPV. 8,17,53,54

In our study population, the rate of cataract extraction was significantly higher after PPV than after SB and PR. Other comparative studies have found similar results ${ }^{43,55}$ and data in the literature generally point to a small risk of cataracts after $\mathrm{SB}^{56}$ and PR. ${ }^{35,38,57,58} \mathrm{~A}$ statistically significant difference in the rate of cataract extraction was detected between PPV with and without SB in this study and is in agreement with observations by Kinori et al. ${ }^{46}$ Therefore, although SB by itself carries a low risk of cataracts, the risk increases significantly when SB is combined with PPV.

The age of patients influenced the need for postsurgical cataract removal, and this is in agreement with other studies. ${ }^{10,59}$ Our inability to detect known factors associated with the rates of cataract surgery, such as diabetes and intraoperative tamponade medium, may be due to the relatively small sample size.

For eyes that developed cataracts, the most common types of cataracts were NSC and PSC, followed by ACC. We observed that NSC and PSC were more common in older and younger patients, respectively. The high frequency of NSC in our study is consistent with the findings of other studies. ${ }^{8,13,14,60-64}$ The incidence of PSC observed in this study is higher than that of other studies, ${ }^{47,50}$ which may be a result of differences in patient characteristics and intraoperative factors. For example, younger patients, diabetic patients, and patients with gas and silicone oil tamponade tend to develop PSC, while older adults tend to develop NSC after PPV. 2,11,65-68

There is information that nuclear sclerosis progresses more rapidly with higher levels of inflammation and vitreous hemorrhage..$^{52}$ Minimally invasive PPV may have the theoretical potential to decrease postoperative NSC. ${ }^{16,17,69}$ This theoretical advantage was not observed in our cohort, as there was no significant difference in the rate of NSC developed after 20-gauge and small gauge PPV. These results are consistent with those of other studies. ${ }^{8,54}$

The results from the sensitivity analyses were overall in accordance with the original analysis, and were not sensitive to the patient's age or to the contribution of both eyes. The inability to detect a statistically significant difference in the change in lens status between silicone oil and gas tamponade may relate to small sample sizes after eliminating 56 eyes.

This study has several limitations. This was a retrospective, uncontrolled, single-center study with potential subjective bias in regards to cataract grading and progression. However, the need for cataract surgery is confirmation of clinically significant cataract progression. It is also difficult to know if patients had cataract surgery elsewhere after being lost to follow-up at the Yale Eye Center. A large, prospective, controlled, multicenter study utilizing objective measures of cataracts such as lens photographs and Lens Opacities Classification System III would be useful to further validate and characterize cataract formation and progression after vitreoretinal procedures.

\section{Conclusion}

In conclusion, NSC and PSC, the two most common types of cataract following vitreoretinal procedures, generally developed or progressed within 2 years after PPV regardless of the gauge of the vitrector. Whereas cataracts commonly occurred after $\mathrm{PPV}+\mathrm{SB}$, they were rare after $\mathrm{SB}$ or $\mathrm{PR}$. Despite having a theoretical advantage, small gauge PPV 
did not protect patients from cataract development or progression after surgery, as compared with 20 -gauge PPV. For patients who undergo PPV, there is a significant probability that visually impairing lenticular opacification will occur in the postoperative period. As a result, many patients will require subsequent cataract surgery within 2 years. Therefore, surgeons and patients should consider the risk of cataract formation when deciding on a vitreoretinal procedure for phakic patients.

\section{Acknowledgments}

This study was supported by the Newman's Own Foundation, Westport, CT, USA; Leir Foundation, New York, NY, USA; and Research to Prevent Blindness Inc., New York, NY, USA.

\section{Disclosure}

The authors report no conflicts of interest in this work. This submission has not been published anywhere previously and it is not simultaneously being considered for any other publication.

\section{References}

1. Cherfan GM, Michels RG, de Bustros S, Enger C, Glaser BM. Nuclear sclerotic cataract after vitrectomy for idiopathic epiretinal membranes causing macular pucker. Am J Ophthalmol. 1991;111(4): 434-438.

2. de Bustros S, Thompson JT, Michels RG, Enger C, Rice TA, Glaser BM. Nuclear sclerosis after vitrectomy for idiopathic epiretinal membranes. Am J Ophthalmol. 1988;105(2):160-164.

3. Hsuan JD, Brown NA, Bron AJ, Patel CK, Rosen PH. Posterior subcapsular and nuclear cataract after vitrectomy. J Cataract Refract Surg. 2001;27(3):437-444.

4. Margherio RR, Cox MS Jr, Trese MT, Murphy PL, Johnson J, Minor LA. Removal of epimacular membranes. Ophthalmology. 1985; 92(8):1075-1083.

5. Michels RG. Vitrectomy for macular pucker. Ophthalmology. 1984; 91(11):1384-1388.

6. Ogura Y, Takanashi T, Ishigooka H, Ogino N. Quantitative analysis of lens changes after vitrectomy by fluorophotometry. Am J Ophthalmol. 1991; 111(2):179-183.

7. Willis AW. [Surgical treatment of idiopathic macular epiretinal membrane]. Ophtalmologie. 1989;3(1):29-30.

8. Rizzo S, Genovesi-Ebert F, Murri S, et al. 25-gauge, sutureless vitrectomy and standard 20-gauge pars plana vitrectomy in idiopathic epiretinal membrane surgery: a comparative pilot study. Graefes Arch Clin Exp Ophthalmol. 2006;244(4):472-479.

9. Panozzo G, Parolini B. Cataracts associated with posterior segment surgery. Ophthalmol Clin North Am. 2004;17(4):557-568, vi.

10. Thompson JT. The role of patient age and intraocular gas use in cataract progression after vitrectomy for macular holes and epiretinal membranes. Am J Ophthalmol. 2004;137(2):250-257.

11. Holekamp NM, Shui YB, Beebe DC. Vitrectomy surgery increases oxygen exposure to the lens: a possible mechanism for nuclear cataract formation. Am J Ophthalmol. 2005;139(2):302-310.

12. Beebe DC, Holekamp NM, Siegfried C, Shui YB. Vitreoretinal influences on lens function and cataract. Philos Trans R Soc Lond B Biol Sci. 2011;366(1568):1293-1300.
13. Fujii GY, De Juan E Jr, Humayun MS, et al. Initial experience using the transconjunctival sutureless vitrectomy system for vitreoretinal surgery. Ophthalmology. 2002;109(10):1814-1820.

14. Fujii GY, De Juan E Jr, Humayun MS, et al. A new 25-gauge instrument system for transconjunctival sutureless vitrectomy surgery. Ophthalmology. 2002;109(10):1807-1812; discussion 1813.

15. Eckardt C. Transconjunctival sutureless 23 -gauge vitrectomy. Retina. 2005;25(2):208-211.

16. Saito Y, Lewis JM, Park I, et al. Nonvitrectomizing vitreous surgery: a strategy to prevent postoperative nuclear sclerosis. Ophthalmology. 1999;106(8):1541-1545.

17. Sawa M, Saito Y, Hayashi A, Kusaka S, Ohji M, Tano Y. Assessment of nuclear sclerosis after nonvitrectomizing vitreous surgery. Am J Ophthalmol. 2001;132(3):356-362.

18. Bahar I, Axer-Siegel R, Weinberger D. Pars plana vitrectomy: comparison of three techniques for the treatment of diabetic vitreous hemorrhage. Ophthalmic Surg Lasers Imaging. 2006;37(5):364-369.

19. Albrieux M, Rouberol F, Bernheim D, Romanet JP, Chiquet C. Comparative study of 23-gauge vitrectomy versus 20 -gauge vitrectomy for the treatment of rhegmatogenous retinal detachment. Graefes Arch Clin Exp Ophthalmol. 2011;249(10):1459-1468.

20. Sayed KM, Naito T, Farouk MM, et al. Twenty five-gauge sutureless vitrectomy versus 20 -gauge vitrectomy in epiretinal membrane surgery. J Med Invest. 2012;59(1-2):69-78.

21. Lott MN, Manning MH, Singh J, Zhang H, Singh H, Marcus DM. 23-gauge vitrectomy in 100 eyes: short-term visual outcomes and complications. Retina. 2008;28(9):1193-1200.

22. Romano MR, Das R, Groenwald C, et al. Primary 23-gauge sutureless vitrectomy for rhegmatogenous retinal detachment. Indian J Ophthalmol. 2012;60(1):29-33.

23. Ibarra MS, Hermel M, Prenner JL, Hassan TS. Longer-term outcomes of transconjunctival sutureless 25 -gauge vitrectomy. Am J Ophthalmol. 2005;139(5):831-836.

24. Tewari A, Shah GK, Fang A. Visual outcomes with 23-gauge transconjunctival sutureless vitrectomy. Retina. 2008;28(2):258-262.

25. Konstantinidis L, Berguiga M, Beknazar E, Wolfensberger TJ. Anatomic and functional outcome after 23 -gauge vitrectomy, peeling, and intravitreal triamcinolone for idiopathic macular epiretinal membrane. Retina. 2009;29(8):1119-1127.

26. Valmaggia C. Pars plana vitrectomy with 25 -gauge instruments in the treatment of idiopathic epiretinal membranes. Klin Monbl Augenheilkd. 2007;224(4):292-296.

27. Gupta OP, Weichel ED, Regillo CD, et al. Postoperative complications associated with 25-gauge pars plana vitrectomy. Ophthalmic Surg Lasers Imaging. 2007;38(4):270-275.

28. Yanyali A, Celik G, Dincyildiz A, Horozoglu F, Nohutcu AF. Primary 23-gauge vitreoretinal surgery for rhegmatogenous retinal detachment. Int J Ophthalmol. 2012;5(2):226-230.

29. Patelli F, Radice P, Zumbo G, Frisone G, Fasolino G. 25-gauge macular surgery: results and complications. Retina. 2007;27(6): 750-754.

30. Shah CP, Ho AC, Regillo CD, Fineman MS, Vander JF, Brown GC. Short-term outcomes of 25-gauge vitrectomy with silicone oil for repair of complicated retinal detachment. Retina. 2008;28(5):723-728.

31. Rizzo S, Belting C, Cresti F, Genovesi-Ebert F. Sutureless 25-gauge vitrectomy for idiopathic macular hole repair. Graefes Arch Clin Exp Ophthalmol. 2007;245(10):1437-1440.

32. Hilton GF, Tornambe PE. Pneumatic retinopexy. An analysis of intraoperative and postoperative complications. The Retinal Detachment Study Group. Retina. 1991;11(3):285-294.

33. Hilton GF, Tornambe PE, Brinton DA, et al. The complication of pneumatic retinopexy. Trans Am Ophthalmol Soc. 1990;88:191-207; discussion 207-210.

34. Kim RY, D'Amico DJ. Postoperative complications of pneumatic retinopexy. Int Ophthalmol Clin. 2000;40(1):165-173.

35. Mougharbel M, Koch FH, Böker T, Spitznas M. No cataract two years after pneumatic retinopexy. Ophthalmology. 1994;101(7):1191-1194. 
36. Tornambe PE, Hilton GF. Pneumatic retinopexy. A multicenter randomized controlled clinical trial comparing pneumatic retinopexy with scleral buckling. The Retinal Detachment Study Group. Ophthalmology. 1989;96(6):772-783; discussion 784.

37. Wirostko WJ, Han DP, Perkins SL. Complications of pneumatic retinopexy. Curr Opin Ophthalmol. 2000;11(3):195-200.

38. Tornambe PE, Hilton GF, Brinton DA, et al. Pneumatic retinopexy. A two-year follow-up study of the multicenter clinical trial comparing pneumatic retinopexy with scleral buckling. Ophthalmology. 1991; 98(7):1115-1123.

39. Chan CK, Lin SG, Nuthi AS, Salib DM. Pneumatic retinopexy for the repair of retinal detachments: a comprehensive review (1986-2007). Surv Ophthalmol. 2008;53(5):443-478.

40. Tornambe PE. Pneumatic retinopexy: the evolution of case selection and surgical technique. A twelve-year study of 302 eyes. Trans Am Ophthalmol Soc. 1997;95:551-578.

41. Heimann H, Bartz-Schmidt KU, Bornfeld N, Weiss C, Hilgers RD, Foerster MH; Scleral Buckling versus Primary Vitrectomy in Rhegmatogenous Retinal Detachment Study Group. Scleral buckling versus primary vitrectomy in rhegmatogenous retinal detachment: a prospective randomized multicenter clinical study. Ophthalmology. 2007; 114(12):2142-2154

42. Azad RV, Chanana B, Sharma YR, Vohra R. Primary vitrectomy versus conventional retinal detachment surgery in phakic rhegmatogenous retinal detachment. Acta Ophthalmol Scand. 2007;85(5):540-545.

43. Oshima Y, Yamanishi S, Sawa M, Motokura M, Harino S, Emi K. Two-year follow-up study comparing primary vitrectomy with scleral buckling for macula-off rhegmatogenous retinal detachment. Jpn J Ophthalmol. 2000;44(5):538-549.

44. Schaal S, Sherman MP, Barr CC, Kaplan HJ. Primary retinal detachment repair: comparison of 1-year outcomes of four surgical techniques. Retina. 2011;31(8):1500-1504.

45. Miki D, Hida T, Hotta K, Shinoda K, Hirakata A. Comparison of scleral buckling and vitrectomy for retinal detachment resulting from flap tears in superior quadrants. Jpn J Ophthalmol. 2001;45(2):187-191.

46. Kinori M, Moisseiev E, Shoshany N, et al. Comparison of pars plana vitrectomy with and without scleral buckle for the repair of primary rhegmatogenous retinal detachment. Am J Ophthalmol. 2011;152(2): 291-297.e2.

47. Cheng L, Azen SP, El-Bradey MH, et al. Duration of vitrectomy and postoperative cataract in the vitrectomy for macular hole study. Am J Ophthalmol. 2001;132(6):881-887.

48. Heimann H, Zou X, Jandeck C, et al. Primary vitrectomy for rhegmatogenous retinal detachment: an analysis of 512 cases. Graefes Arch Clin Exp Ophthalmol. 2006;244(1):69-78.

49. Leonard RE 2nd, Smiddy WE, Flynn HW Jr, Feuer W. Long-term visual outcomes in patients with successful macular hole surgery. Ophthalmology. 1997;104(10):1648-1652.

50. Cole CJ, Charteris DG. Cataract extraction after retinal detachment repair by vitrectomy: visual outcome and complications. Eye (Lond). 2009;23(6):1377-1381.

51. Thompson JT, Glaser BM, Sjaarda RN, Murphy RP. Progression of nuclear sclerosis and long-term visual results of vitrectomy with transforming growth factor beta-2 for macular holes. Am JOphthalmol. 1995;119(1):48-54.
52. Smiddy WE, Feuer W. Incidence of cataract extraction after diabetic vitrectomy. Retina. 2004;24(4):574-581.

53. Faia LJ, McCannel CA, Pulido JS, Hatfield RM, Hatfield ME, McNulty VE. Outcomes following 25-gauge vitrectomies. Eye (Lond). 2008;22(8):1024-1028.

54. Almony A, Holekamp NM, Bai F, Shui YB, Beebe D. Small-gauge vitrectomy does not protect against nuclear sclerotic cataract. Retina. 2012;32(3):499-505.

55. Day S, Grossman DS, Mruthyunjaya P, Sloan FA, Lee PP. One-year outcomes after retinal detachment surgery among medicare beneficiaries. Am J Ophthalmol. 2010;150(3):338-345.

56. Amemiya T, Yoshida H, Harayama K, Miki M, Koizumi K. Long-term results of retinal detachment surgery. Ophthalmologica. 1978;177(2): 64-69.

57. Zaidi AA, Alvarado R, Irvine A. Pneumatic retinopexy: success rate and complications. Br J Ophthalmol. 2006;90(4):427-428.

58. Chen SN, Hwang JF. Treatment of rhegmatogenous retinal detachment in teenagers by pneumatic retinopexy technique. Am J Ophthalmol. 2007;143(2):217-221.

59. Melberg NS, Thomas MA. Nuclear sclerotic cataract after vitrectomy in patients younger than 50 years of age. Ophthalmology. 1995;102(10):1466-1471.

60. Paques M, Massin P, Santiago PY, Spielmann AC, Le Gargasson JF, Gaudric A. Late reopening of successfully treated macular holes. $\mathrm{Br} J$ Ophthalmol. 1997;81(8):658-662.

61. Brooks HL Jr. Macular hole surgery with and without internal limiting membrane peeling. Ophthalmology. 2000;107(10):1939-1948; discussion 1948-1949.

62. Kotecha AV, Sinclair SH, Gupta AK, Tipperman R. Pars plana vitrectomy for macular holes combined with cataract extraction and lens implantation. Ophthalmic Surg Lasers. 2000;31(5):387-393.

63. Haritoglou C, Reiniger IW, Schaumberger M, Gass CA, Priglinger SG, Kampik A. Five-year follow-up of macular hole surgery with peeling of the internal limiting membrane: update of a prospective study. Retina. 2006;26(6):618-622.

64. Hilton GF, Josephberg RG, Halperin LS, et al. Office-based sutureless transconjunctival pars plana vitrectomy. Retina. 2002;22(6):725-732.

65. Novak MA, Rice TA, Michels RG, Auer C. The crystalline lens after vitrectomy for diabetic retinopathy. Ophthalmology. 1984;91(12): 1480-1484.

66. Hakin KN, Lavin MJ, Leaver PK. Primary vitrectomy for rhegmatogenous retinal detachment. Graefes Arch Clin Exp Ophthalmol. 1993; 231(6):344-346.

67. Blodi BA, Paluska SA. Cataract after vitrectomy in young patients. Ophthalmology. 1997;104(7):1092-1095.

68. Spencer WH. Ophthalmic Pathology: An Atlas and Textbook. 3rd ed. Philadelphia, PA: WB Saunders; 1985.

69. Sawa M, Ohji M, Kusaka S, et al. Nonvitrectomizing vitreous surgery for epiretinal membrane long-term follow-up. Ophthalmology. 2005; 112(8):1402-1408. 


\section{Supplementary material}

Table SI Distribution of lens grading for surgical eyes before vitreoretinal surgery

\begin{tabular}{|c|c|c|c|c|c|c|}
\hline Lens grading & 20-gauge PPV & Small gauge PPV & PR & SB & $\mathbf{P P V}+\mathbf{S B}$ & $P$-value \\
\hline 0.0 & 31 & 24 & 4 & 24 & 25 & \\
\hline 0.5 & 0 & 1 & I & 0 & 0 & \\
\hline 1.0 & 17 & 12 & 6 & 7 & 6 & \\
\hline 1.5 & 2 & 4 & I & 2 & 2 & \\
\hline 2.0 & 9 & 8 & 2 & 2 & 2 & \\
\hline 2.5 & 0 & I & 0 & 0 & 0 & 0.035 \\
\hline 3.0 & 0 & 0 & 0 & 0 & 0 & \\
\hline 3.5 & 0 & 0 & 0 & 0 & 0 & \\
\hline 4.0 & 0 & 0 & 0 & 0 & 0 & \\
\hline Mean & 0.644 & 0.740 & 0.857 & 0.400 & 0.371 & \\
\hline Standard deviation & 0.755 & 0.810 & 0.691 & 0.639 & 0.634 & \\
\hline
\end{tabular}

Abbreviations: PPV, pars plana vitrectomy; PR, pneumatic retinopexy; SB, scleral buckle; PPV+SB, combined pars plana vitrectomy plus scleral buckle.

\section{Publish your work in this journal}

Clinical Ophthalmology is an international, peer-reviewed journal covering all subspecialties within ophthalmology. Key topics include: Optometry; Visual science; Pharmacology and drug therapy in eye diseases; Basic Sciences; Primary and Secondary eye care; Patient Safety and Quality of Care Improvements. This journal is indexed on

Submit your manuscript here: http://www.dovepress.com/clinical-ophthalmology-journal
Dovepress

PubMed Central and CAS, and is the official journal of The Society of Clinical Ophthalmology (SCO). The manuscript management system is completely online and includes a very quick and fair peer-review system, which is all easy to use. Visit http://www.dovepress.com/ testimonials.php to read real quotes from published authors. 